\title{
Application of moderate resolution imaging spectroradiometer snow cover maps in modeling snowmelt runoff process in the central Zab basin, Iran (Erratum)
}

\author{
Himan Shahabi, ${ }^{\text {a,* Saeed Khezri, }}{ }^{\text {b }}$ Baharin Bin Ahmad, ${ }^{\text {a }}$ \\ and Tajul Ariffin Musa ${ }^{\mathrm{c}}$
}

${ }^{a}$ Universiti Teknologi Malaysia, Institute of Geospatial Science and Technology, Skudai, Johor Bahru, Malaysia

${ }^{b}$ University of Kurdistan, Department of Physical Geography, Faculty of Natural Resources, Iran ${ }^{c}$ Universiti Teknologi Malaysia, UTM-GNSS and Geodynamics Research Group, Faculty of Geoinformation and Real Estate, Skudai, Johor, Malaysia

[DOI: 10.1117/1.JRS.15.029901]

This article [J. of Applied Remote Sensing, 8(1), 084699 (2014). https://doi.org/10.1117/1 .JRS.8.084699] has had several figures republished for clarity. Values in the scale bars in Figs. 1 and 2 were unclear. Those figures have been reconfigured to be more readable. In Figs. 3 and 6-9, the position of the study area was unclear because of the use of the transverse Mercator coordinate system. The figures have been revised to better represent the study area.

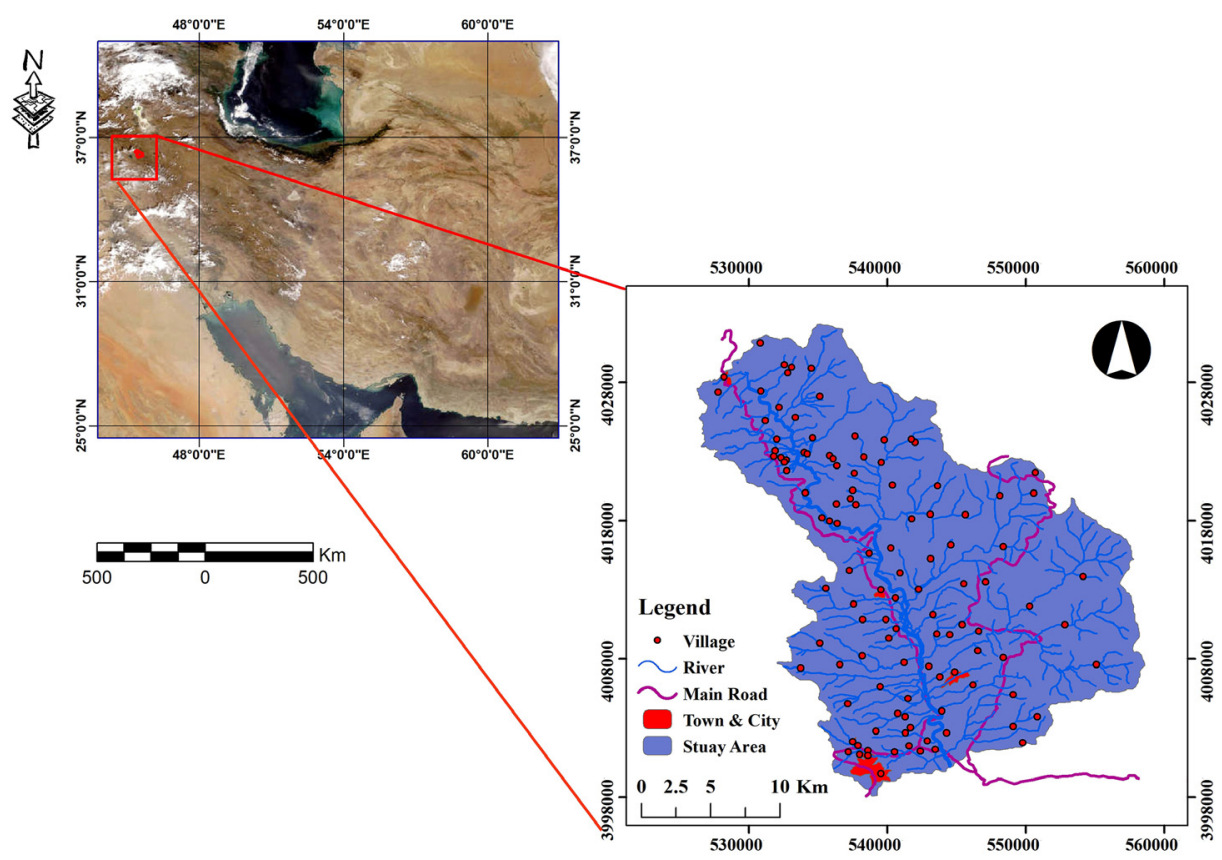

Fig. 1 Geographical position of central Zab basin.

*Address all correspondence to Himan Shahabi, himanshahabi@gmail.com 


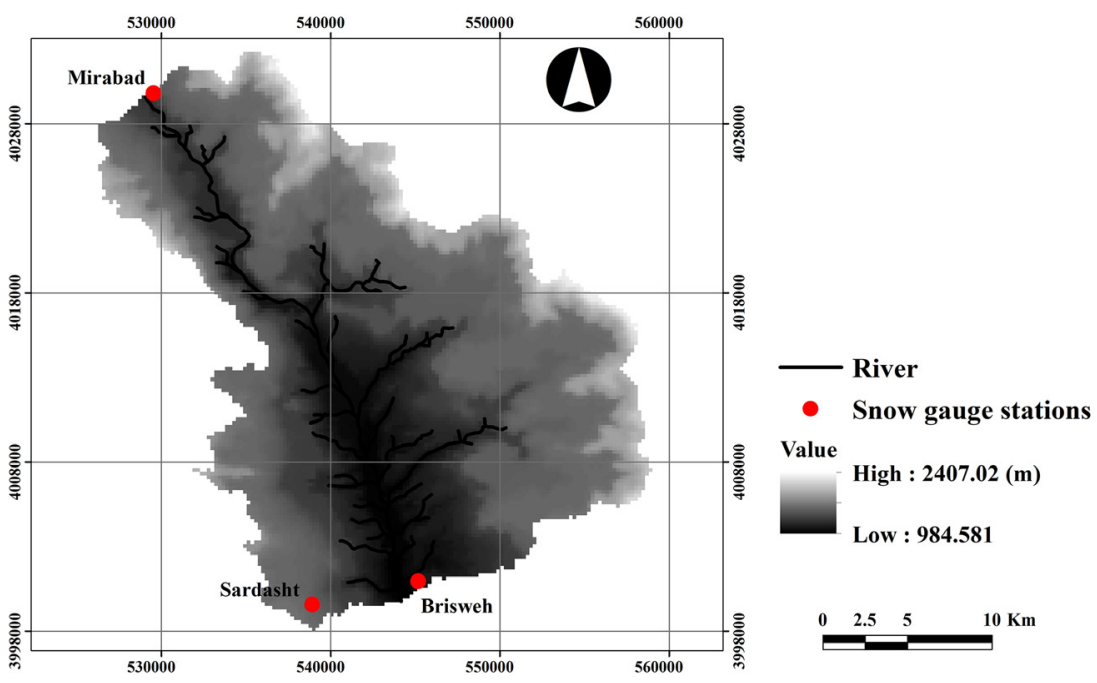

Fig. 2 Location of snow gauge stations location on DEM of central Zab basin extracted from an advanced spaceborne thermal emission and reflection radiometer image.

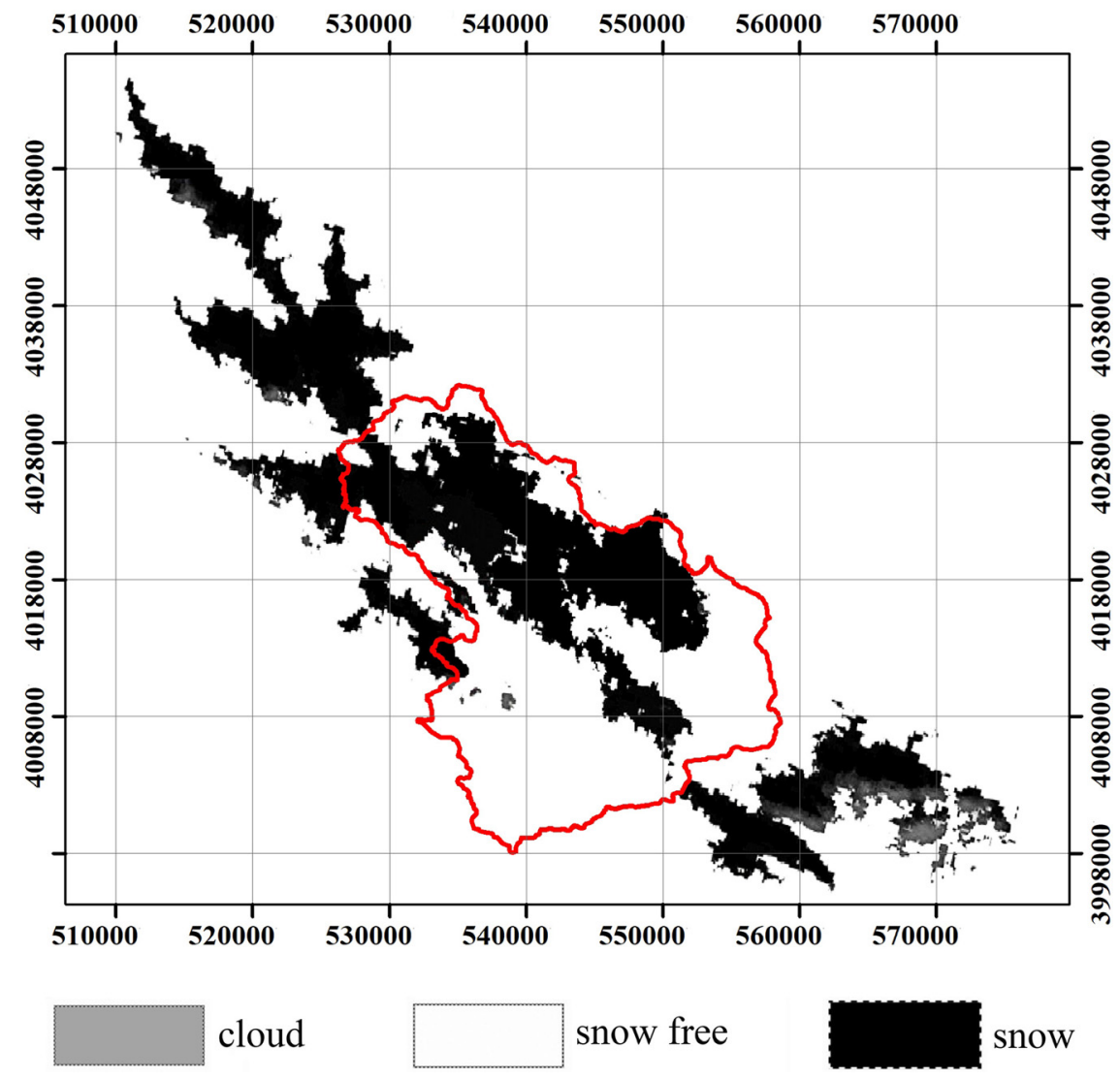

Fig. 3 Snow, snow free, and cloud covers extracted from moderate resolution imaging spectroradiometer (MODIS) satellite images taken on February 14, 2011. 


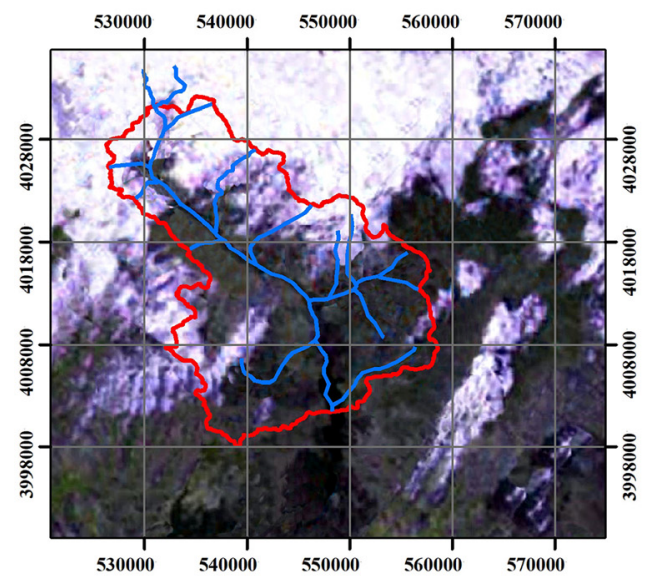

(a)

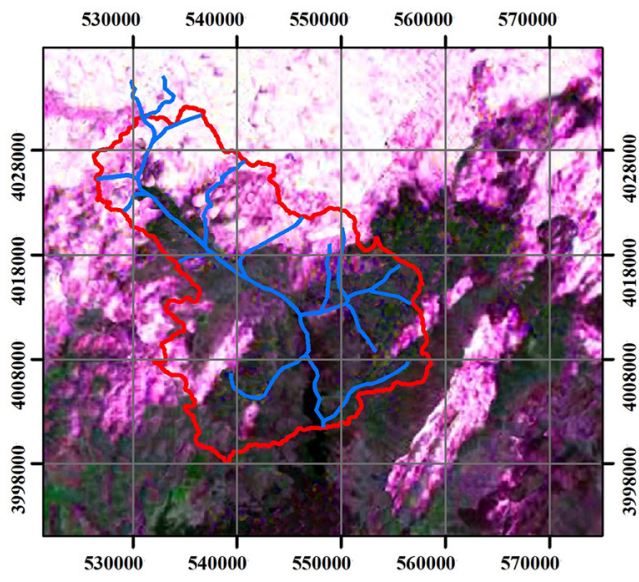

(b)

Fig. 6 Accuracy test of the process of geometric correction using the layer of basin waterways before (a) and after (b) the process of geometric correction.

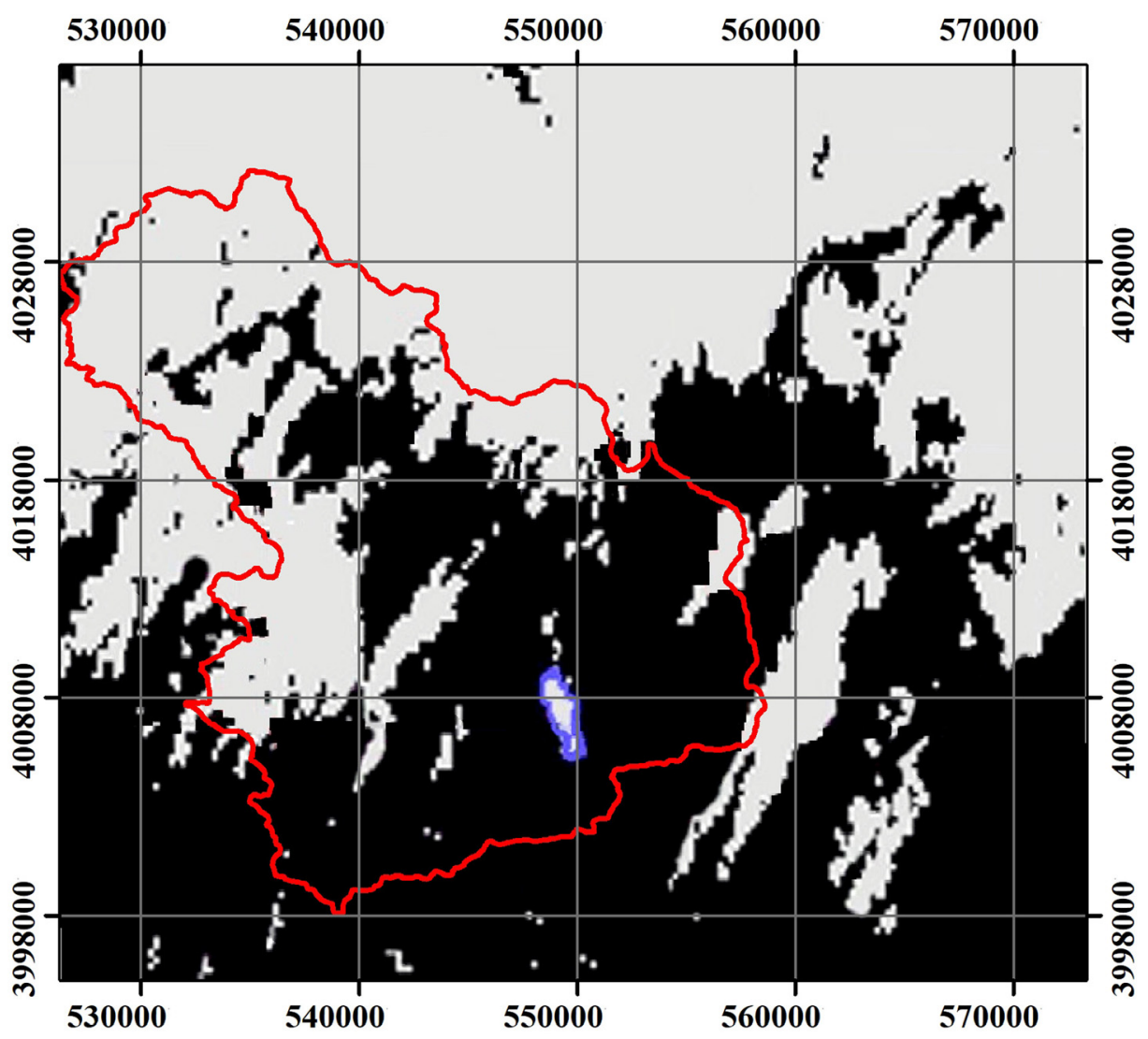

Fig. 7 Separated snow by normalized difference snow index (NDSI) method. 


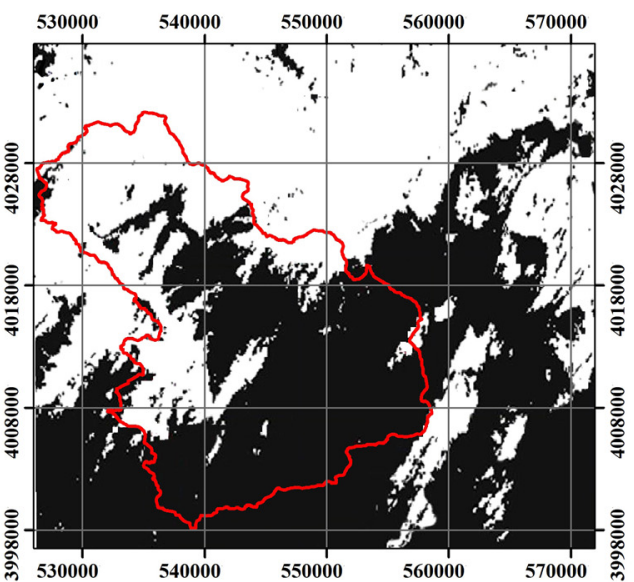

(a)

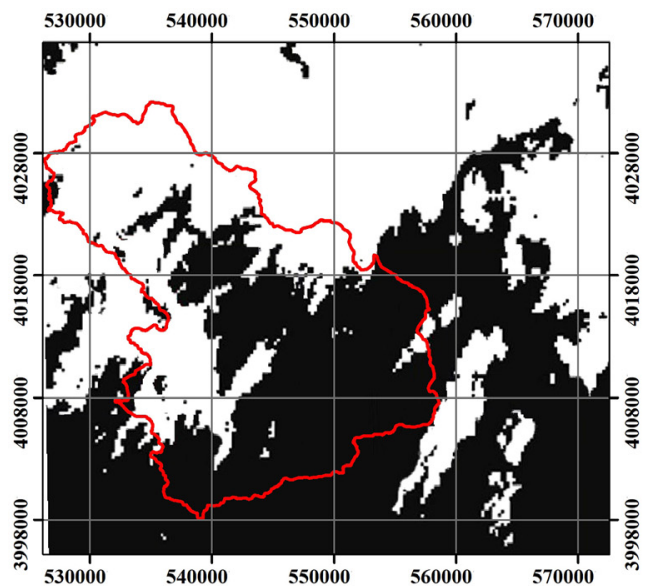

(b)

Fig. 8 Reflection band 2 (a) and band 4 (b) reflectance criteria used for snow separation.

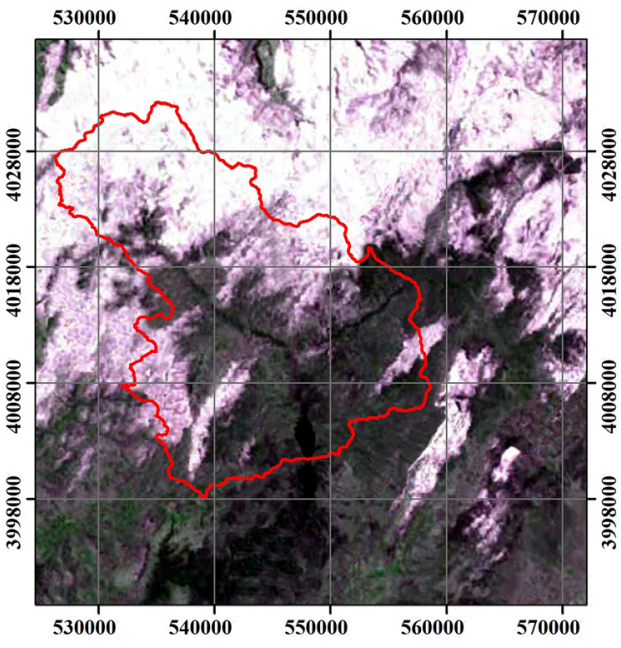

(a)

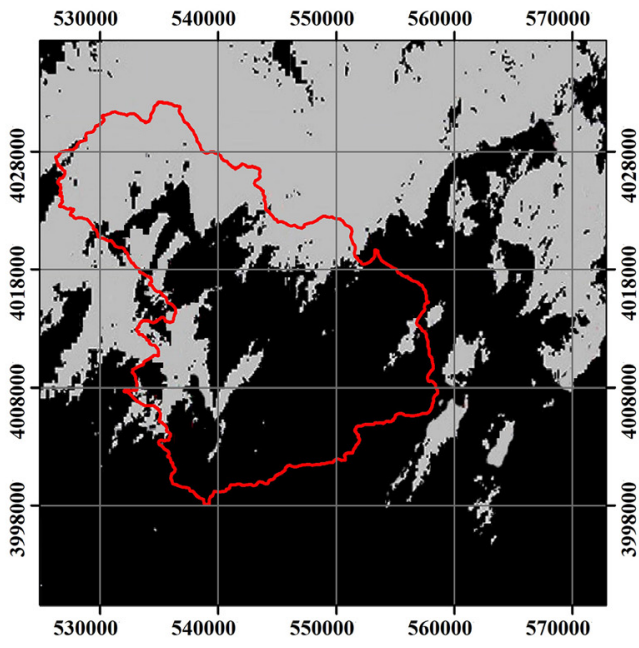

(b)

Fig. 9 The real MODIS image (a) and snow separated by the NDSI method (b).

All versions of the article were corrected on 26 May 2021. 